\title{
Uptake of Intermittent Preventive Treatment for Malaria during Pregnancy with Sulphadoxine-Pyrimethamine (IPTp-SP) in Malawi after adoption of updated World Health Organization policy: An Analysis of Demographic and Health Survey 2015-2016
}

Steven Chifundo Azizi ( $\square$ steve_aziz@hotmail.com )

Research article

Keywords: Pregnancy, Intermittent preventive treatment, Sulphadoxine-pyrimethamine, malaria, Antenatal care, Malawi

Posted Date: January 10th, 2020

DOI: https://doi.org/10.21203/rs.2.20575/v1

License: @ (i) This work is licensed under a Creative Commons Attribution 4.0 International License. Read Full License

Version of Record: A version of this preprint was published at BMC Public Health on March 16th, 2020. See the published version at https://doi.org/10.1186/s12889-020-08471-5. 


\section{Abstract}

Background Malawi adopted the 2012 updated Word Health Organization (WHO) Intermittent preventive treatment of malaria during pregnancy with sulphadoxine-pyrimethamine (IPTp-SP) policy in 2013. This study aimed to estimate the proportion of and identify factors associated with the uptake of at least three doses of IPTp-SP among pregnant women in Malawi after the adoption of updated WHO IPTp-SP policy.

Methods The 2015-16 Malawi Demographic and Health Survey dataset was used. Of 1,219 women aged 15-49 years who had live births and the children were born after date of July 2015, 1,069 women were included in the analysis. Bivariate and multiple logistic regression were used in data analysis. The statistical analysis took into account complex survey sample design.

Results Of the 1,069 women, 447 (42\%, 95\% Cl: 38.1-45.6) received three (optimal) or more doses of IPTp-SP. Less than half (47\%) managed to attend at least four antenatal care (ANC) clinics. Only 52\% received optimal SP doses among those who made at least four ANC visits. Only the number of ANC visits was associated with the optimal uptake of SP. Women who attended ANC three times only and those who visited ANC once or twice only were less likely to receive at least three doses of SP than those who managed to attend ANC at least four times during pregnancy $(\mathrm{AOR}=0.71,95 \% \mathrm{Cl} 0.49-1.02)$ and $(\mathrm{AOR}=0.12,95 \% \mathrm{Cl} 0.06-0.21)$ respectively.

Conclusions To achieve effective malaria prevention in pregnancy, IPTP-SP is used alongside other interventions. However, there is low uptake of optimal SP doses in Malawi, and this seems to be associated with the number of ANC visits. There is limited effectiveness of increased number of ANC visits on the uptake of optimal SP doses. Further research should be done to explore health systems factors affecting uptake of optimal IPTp-SP doses during pregnancy.

\section{Background}

With estimated 125 million pregnant women at risk of malaria infection each year globally and 30 million come from sub-Saharan Africa (SSA) [1], malaria in pregnancy (MiP) ranks among the major public health problems in SSA [2-5]. Available statistics have revealed that 75,000-200,000 infants and 10, 000 women deaths annually are attributed to MiP $[1,6]$. Pregnant women are susceptible to severe Plasmodium falciparum infection because of alteration of acquired antimalarial immunity due to parasites (VAR2CSA) that sequester in the placenta $[7,8]$. The Plasmodium falciparum impairs the capacity of the placenta to transport amino acids from maternal blood to the foetus; and therefore contributing to lower birth weights (LBW) [9]. Other consequences of malaria infection in pregnancy are increased risk of severe anaemia, cerebral malaria, pre-term delivery, intra-uterine growth retardation, maternal death and increased risk to unborn baby from miscarriage [10-13]. It has been estimated that Plasmodium falciparum infections in pregnancy contributes to around $11 \%$ of neonatal deaths due to LBW in endemic areas in Africa $[6,14,15]$.

In Malawi, malaria is hyper-endemic and transmission trend rises in the rainy season (October to April) and in areas with high temperatures especially around lakeshore and lower Shire Valley [16]. Ninety-eight percent of malaria infections are caused by Plasmodium falciparum transmitted by Anopheles funestus, A. gambiae, and A. arabiensis mosquito vectors [16]. To mitigate malaria burden among pregnant women, Malawi was the first country to introduce Intermittent Preventive Treatment of malaria during pregnancy with sulphadoxinepyrimethamine (IPTp-SP) in 1993 [17]. Sulphadoxine-pyrimethamine (SP) is an antifolate drug that inhibits cell 
multiplication of malaria parasites hence, placental malaria infection is prevented or Plasmodium falciparum active in the placenta is controlled [7].

In 2004, World Health Organisation (WHO) recommended a minimum of two doses of IPTp with SP among other malaria prevention and control approaches during pregnancy [18, 19]. In October 2012, however, WHO updated the policy to at least three doses after acknowledgement from Evidence Review Group (ERG) that reviewed research evidence on efficacy of IPTp-SP and its adverse outcomes in preventing MiP [20-25]. The updated policy further says that IPTp with SP should be administered at each antenatal visit, with the first dose given early in the second trimester and successive doses administered at monthly intervals until the time of delivery [26]. Malawi adopted the updated policy in 2013 [27]. WHO envisioned the policy would increase IPTp-SP uptake because the World Health Organisation also recommended at least four ANC visits during the second and third trimesters of pregnancy under the Focused antenatal care (FANC) model $[20,28]$. Therefore there is ample chance to attain a high proportion of women receiving at least three doses; and if a pregnant woman does not receive SP at each scheduled ANC visits within the recommended IPTp-SP administration period, it would be deemed as a missed opportunity [19].

Since WHO updated the IPTp-SP policy, there is paucity of studies that managed nationally to estimate proportions of uptake of at least three doses of IPTp-SP and identified factors associated with it among pregnant women in Malawi such as Azizi et. al study [29]. This study, however, is limited to a particular district. Globally, studies have revealed that uptake of at least two doses of IPTp-SP is associated with number of ANC visits [5, 21, 29-38], directly observed therapy (DOT) [5, 29, 37, 39, 40], residential area [21, 29, 41], age of woman [41], education level and socioeconomic status [42], parity [5, 41], timing of initial ANC visit [5, 36, 43], knowledge about malaria/IPTp-SP $[5,37]$ and stockouts of the commodity $[5,37,44]$. This study aimed to contribute to identifying factors associated with completion of recommended doses of SP during pregnancy using the updated WHO policy in resource limited settings from a nationally representative sample. The aims of the study were to estimate the proportion of and identify factors associated with the uptake of at least three doses of IPTp with SP among pregnant women in Malawi.

\section{Methods}

\section{Study design and study setting}

This was a cross-sectional survey carried out to provide estimates of basic demographic and health indicators for Malawi nation. The study was nationally representative, with all 28 districts included in the sample, stratified by residential area (urban and rural). It yielded 56 sampling strata.

Weighted sample was selected in two stages. In the first stage, 850 standard enumeration areas (SEAs) also known as clusters (173 SEAs in urban areas and 677 in rural areas) were selected with probability proportional to the SEA size. The list of households in each selected SEA served as the sampling frame for the second stage. Some of the selected SEAs were large, hence to reduce the work of household listing, each large SEA (more than 250 households) was segmented. From each of the segmented SEAs, one segment was selected for the survey with probability proportional to the segment size. In the second stage, a fixed number of 30 households per urban cluster and 33 per rural cluster were randomly selected from each cluster's household listing. A total of 27,516 households were selected, of which 26,564 were occupied. Among the occupied households, 26,361 were interviewed (99\% response). From the interviewed households, 25,146 eligible women were identified for 
individual interviews and only 24,562 women were successfully interviewed ( $98 \%$ response). All women aged $15-$ 49 years old were interviewed if they were permanent residents of, or had stayed in the household in the previous night before the survey in the period between October 2015 and February 2016. Detailed methodology has been published elsewhere [45].

\section{Study population}

The target population was all women aged 15-49 years with live births one-year-old or less preceding the survey in Malawi between the years 2015 and 2016. The study was based on data from the 2015-16 Malawi Demographic and Health Survey (MDHS). Malawi National Statistical Office conducted the survey from 19 October 2015 to 18 February 2016

\section{Inclusion and exclusion criteria}

The analysis included all women age 15-49 with live children born at least in August 2015, because the implementation of the updated policy was nationally full-fledged in October 2014. On the other hand, study participants who had missing data on at least one of key variables used in the analysis were excluded from the analysis.

\section{Sample selection}

Out of 24, 562 women who completed the interviews, 1,219 had live births and the children were born after month of July 2015. About 120 women were excluded from analysis because of lack of information on at least one variable used in the analysis. The final sample size used in the analysis was 1, 084 (unweighted) and 1,069 (weighted) (Figure 1).

\section{Insert Figure 1 here}

\section{Data extraction and variables used in the analysis}

Guided by literature review, data were extracted for analysis based on variables that are theoretically and empirically linked to uptake of IPTp-SP as follows: (a) the outcome variable was IPTp-SP uptake, categorised as two doses or less ( $\leq 2$ doses) and three doses or more (3+ doses, also known as optimal dose); (b) explanatory variables were woman's residential area, woman's level of education, woman's age, woman's occupation, wealth, marital status, region, parity, timing of the first ANC visit, and number of ANC visits (Table 1). The data covering these variables were extracted from the 2015-16 MDHS women dataset that were collected using woman's questionnaire. 
Table 1: Variables used in the study

\begin{tabular}{lll}
$\begin{array}{l}\text { Outcome } \\
\text { variable }\end{array}$ & Definition & Category \\
\hline IPTp-SP uptake & $\begin{array}{l}\text { Two or less }(\leq 2) \text { doses is incomplete and three or more }(3+) \text { is } \\
\text { optimal }\end{array}$ & $\leq 2$ doses \\
\cline { 2 - 3 } & $3+$ doses
\end{tabular}

\section{Explanatory variable}

\begin{tabular}{|c|c|c|}
\hline \multirow[t]{2}{*}{ Residence } & \multirow[t]{2}{*}{ Area of woman's residence (urban or rural) } & Rural \\
\hline & & Urban \\
\hline \multirow[t]{3}{*}{ Education } & \multirow[t]{3}{*}{ Level of education of woman } & No formal education \\
\hline & & Primary \\
\hline & & Secondary or higher \\
\hline \multirow[t]{6}{*}{ Age } & \multirow[t]{6}{*}{ Age group of a woman } & $15-19$ \\
\hline & & $20-24$ \\
\hline & & $25-29$ \\
\hline & & $30-34$ \\
\hline & & $35-39$ \\
\hline & & $40+$ \\
\hline \multirow[t]{3}{*}{ Occupation } & \multirow[t]{3}{*}{ Woman's occupation } & Unemployed \\
\hline & & Self-employed \\
\hline & & Employed \\
\hline \multirow[t]{5}{*}{ Wealth } & \multirow[t]{5}{*}{ Household's wealth from which a woman is an occupant } & Poorest \\
\hline & & Poorer \\
\hline & & Middle \\
\hline & & Richer \\
\hline & & Richest \\
\hline \multirow[t]{3}{*}{ Marital status } & \multirow[t]{3}{*}{ Marital status of a woman } & Married \\
\hline & & $\begin{array}{l}\text { Divorced/separated/ } \\
\text { widowed }\end{array}$ \\
\hline & & Never married \\
\hline \multirow[t]{3}{*}{ Region } & & Southern \\
\hline & & Central \\
\hline & & Northern \\
\hline
\end{tabular}


Parity Number of birth that a woman had after 20 weeks gestation One child

Two children

Three children

Four children

Five or more children

Timing of 1st Age (in months) of the pregnancy a woman visited antenatal care ANC visit 1st trimester (1-12 weeks)

2nd trimester (13-26 weeks)

3rd trimester $(27+$ weeks)

$4+$ her gestation period
3

$1-2$

The woman's questionnaire collected information from all eligible women age 15-49 who were asked questions on (a) background characteristics such as age, education, media exposure, (b) reproduction: children ever born, birth history, current pregnancy, (c) family planning: knowledge and use of contraception, sources of contraceptive methods, information on family planning, (d) maternal and child health, breastfeeding, and nutrition: prenatal care, delivery, postnatal care, breastfeeding and complementary feeding practices, vaccination coverage, prevalence and treatment of diarrhoea, acute respiratory infection (ARI), fever, knowledge and use of oral rehydration therapy (ORT), breastfeeding, and feeding practices, (e) marriage and sexual activity: marital status, age at first marriage, number of unions, age at first sexual intercourse, recent sexual activity, number and type of sexual partners, use of condoms, (f) fertility preferences: desire for more children, ideal number of children, gender preferences, intention to use family planning, $(\mathrm{g})$ husband's background and woman's work: husband's age, level of education, and occupation, and woman's occupation and sources of earnings, (h) STDs and HIV: knowledge of STDs and HIV, methods of transmission, sources of information, behaviours to avoid STDs and HIV, and stigma, (i) knowledge, attitudes, and behaviours related to other health issues such as injections, smoking, fistula, tuberculosis, (j) adult and maternal mortality and ( $\mathrm{k}$ ) domestic violence [45].

\section{Data management}

Data extraction, cleaning and analysis were done using Stata version 16 (Stata Corp, College Station, Tx, USA).

\section{Data analysis}


Proportions and frequencies were used to summarize categorical variables in descriptive analysis. On the other hand, bivariate and multiple logistic regressions were used in analytical analysis.

Four stages of logistic regression modelling of survey data were applied as specified by Heeringa, West and Berglund [46]; and Hosmer, Lemeshow and Sturdivant [47]. First, bivariate analyses of the relationship of outcome to individual explanatory variable candidates were performed. Second, explanatory variables that had a bivariate association with the outcome at significance were selected as candidates for the main effects in a multivariate logistic regression model. An initial model-building process using multivariate logistic regression analysis was done to further examine the association (measure of effect) between the outcome and each explanatory variable while controlling the effects of other explanatory variables. The model estimated adjusted odds ratios (AOR). The level of significance used was 5\% (0.05), two-tailed at 95\% confidence interval ( $\mathrm{Cl})$. Third, the contribution of each explanatory variable to the multivariate model was evaluated using Wald test at $5 \%$ significant level (Table 2). Table 2 shows one of the six adjusted Wald tests is statistically significant for categorical predictors, namely number of ANC visits, in this initial model. This suggests that the parameters associated with number of ANC visits in this logistic regression model are significantly different from zero and that the variable may be important predictor of uptake of at least three doses of SP when adjusting for the relationships of the other predictor variables with the outcome. Therefore, at this stage in the model-building process, only 'number of ANC visits' variable was retained of all of the candidate main effects. Thus, second model-building process included 'number of ANC visits' categorical predictors only, which had similar odds ratios as the adjusted one. Lastly, scientifically justified interactions among the explanatory variables were also checked and there were no significant interactions observed.

The statistical analysis took into account complex characteristics of the survey sample design by allowing adjustments for stratification, clustering and weighting for unequal selection probabilities.

\section{Table 2: Design-Adjusted Wald tests for the parameters associated with categorical predictors in the initial multiple logistic regression model}

\begin{tabular}{lll} 
Categorical Predictor & F-Test Statistic & $P$-value \\
\hline Education level & $F_{(2,563)}=0.30$ & 0.7399 \\
\hline Age group & $F_{(5,560)}=0.86$ & 0.5088 \\
\hline Occupation & $F_{(2,563)}=0.14$ & 0.8736 \\
\hline Wealth status & $F_{(4,561)}=0.92$ & 0.4527 \\
\hline Parity & $F_{(4,561)}=0.37$ & 0.8316 \\
\hline Timing of $1^{\text {st }}$ ANC visit & $F_{(2,563)}=1.23$ & 0.2925 \\
\hline Number of ANC visits & $F_{(2,563)}=25.01$ & $<0.001 *$
\end{tabular}

* Design-adjusted Wald tests significant at the 0.05 level

\section{Ethical considerations}


The MDHS protocol was reviewed and approved by Malawi's National Health Sciences Research Committee and ICF Institutional Review Board [45]. Interviewers informed prospective participants about the purpose of the study, procedures required of them if recruited, and that they had the right to volunteer whether or not to participate in the study [45]. Informed consent was obtained from each participant before administering the questionnaire and the respondents were assured of privacy and confidentiality [45].

\section{Results}

\section{Overall proportion of women who took three or more doses of IPTP-SP}

Of the 1,069 (weighted count) women, 447 (42\%, 95\% Cl: 38.1-45.6) received three (optimal) or more doses of IPTp-SP and 622 (58\%, 95\% Cl: 54.4-61.9) took less than three doses.

Socio-demographic characteristics of participants and uptake of IPTp-SP

Out of 1,069 women, 903 (84.5\%) resided in rural areas and of these women, only $372(41 \%)$ took at least three doses of IPTp-SP. Of 165 women who lived in urban areas, $45 \%$ took three or more doses of IPTp-SP during pregnancy. There is no statistically significant association between residential area and uptake of SP optimal doses $(p=0.5270)$. Almost two-thirds $(65 \%)$ of participants had attended primary school and $12 \%$ had no formal education. Women who had attained secondary or higher education level had highest uptake of three or more doses of IPTp-SP (49\%) than the rest of women who achieved primary or no formal education levels. There is insignificant relationship between IPTp-SP uptake and education level $(p=0.1243)$. Participants in the age group 25-29 had the highest uptake of optimal SP doses compared to the rest of the age groups. Uptake of optimal dosages of SP varied significantly across age groups $(p=0.0318)$. More than half $(51 \%)$ of employed women received at least three doses, the uptake of three or more dosages of SP were not statistically significant across occupation status $(p=0.1259)$. The richer and richest women had the highest uptake of optimal doses of SP than the rest. The uptake of the optimal doses of SP was not significantly different across the regions $(p=0.9412)$ (Table 3). 
Table 3: Sociodemographic characteristics of participants by IPTp with SP uptake

\begin{tabular}{|c|c|c|c|c|c|}
\hline \multirow[t]{2}{*}{ Characteristic } & \multirow[t]{2}{*}{$\begin{array}{l}\mathrm{N}^{\dagger} \text { Total }= \\
1069\end{array}$} & \multicolumn{2}{|c|}{$\begin{array}{l}\% \text { women took } 3+ \\
\text { doses }\end{array}$} & \multirow[t]{2}{*}{ Rao-Scott F-test } & \multirow[t]{2}{*}{ p-value } \\
\hline & & $\mathrm{n}^{\ddagger}(\%)$ & $(95 \% \mathrm{Cl})$ & & \\
\hline \multicolumn{6}{|l|}{ Residence } \\
\hline Urban & 165 & $74(45.0)$ & $\begin{array}{l}34.3- \\
56.1\end{array}$ & $F(1,564)=0.4006$ & 0.5270 \\
\hline Rural & 913 & $\begin{array}{l}372 \\
(41.2)\end{array}$ & $\begin{array}{l}37.3- \\
45.2\end{array}$ & & \\
\hline
\end{tabular}

Education

\begin{tabular}{|c|c|c|c|c|c|}
\hline No formal education & 125 & 48 (38.6) & $\begin{array}{l}29.1- \\
49.1\end{array}$ & $\begin{array}{l}F(2.00,1126.79)= \\
2.0890\end{array}$ & $0.1243^{*}$ \\
\hline Primary & 699 & $\begin{array}{l}280 \\
(40.0)\end{array}$ & $\begin{array}{l}35.7- \\
44.5\end{array}$ & & \\
\hline Secondary or higher & 245 & $\begin{array}{l}119 \\
(48.5)\end{array}$ & $\begin{array}{l}40.7- \\
56.3\end{array}$ & & \\
\hline \multicolumn{6}{|l|}{ Age group } \\
\hline $15-19$ & 168 & $66(39.5)$ & $\begin{array}{l}31.4- \\
48.2\end{array}$ & $\begin{array}{l}F(4.85,2736.04)= \\
2.4753\end{array}$ & $0.0318 *$ \\
\hline $20-24$ & 356 & $\begin{array}{l}160 \\
(45.1)\end{array}$ & $\begin{array}{l}38.4- \\
52.0\end{array}$ & & \\
\hline $25-29$ & 237 & $\begin{array}{l}117 \\
(49.2)\end{array}$ & $\begin{array}{l}40.9- \\
57.5\end{array}$ & & \\
\hline $30-34$ & 156 & $56(36.0)$ & $\begin{array}{l}28.5- \\
44.3\end{array}$ & & \\
\hline $35-39$ & 108 & $34(31.7)$ & $\begin{array}{l}22.6- \\
42.5\end{array}$ & & \\
\hline $40+$ & 44 & 13 (29.3) & $\begin{array}{l}17.2- \\
45.2\end{array}$ & & \\
\hline \multicolumn{6}{|l|}{ Occupation } \\
\hline Unemployed & 392 & $\begin{array}{l}173 \\
(44.2)\end{array}$ & $\begin{array}{l}38.4- \\
50.8\end{array}$ & $\begin{array}{l}F(1.99,1121.60)= \\
2.0785\end{array}$ & $0.1259 *$ \\
\hline Self-employed & 578 & $\begin{array}{l}224 \\
(38.7)\end{array}$ & $\begin{array}{l}33.9- \\
43.9\end{array}$ & & \\
\hline Employed & 99 & $50(50.5)$ & $\begin{array}{l}40.3- \\
63.2\end{array}$ & & \\
\hline \multicolumn{6}{|l|}{ Wealth } \\
\hline Poorest & 234 & $96(41.3)$ & $\begin{array}{l}33.6- \\
49.4\end{array}$ & $\begin{array}{l}F(3.90,2196.87)= \\
1.8457\end{array}$ & $0.1193^{\star}$ \\
\hline
\end{tabular}




\begin{tabular}{|c|c|c|c|c|c|}
\hline Poorer & 238 & $89(37.4)$ & $\begin{array}{l}30.2- \\
45.1\end{array}$ & & \\
\hline Middle & 207 & $74(35.7)$ & $29.0-43.1$ & & \\
\hline Richer & 199 & $96(48.1)$ & $\begin{array}{l}39.7- \\
56.6\end{array}$ & & \\
\hline Richest & 190 & $91(48.0)$ & $\begin{array}{l}38.2- \\
57.9\end{array}$ & & \\
\hline \multicolumn{6}{|l|}{ Marital status } \\
\hline Married & 935 & $\begin{array}{l}393 \\
(42.0)\end{array}$ & $\begin{array}{l}38.1- \\
46.0\end{array}$ & $\begin{array}{l}F(1.97,1113.02)= \\
0.4090\end{array}$ & 0.6617 \\
\hline Divorced/separated/widowed & 72 & $26(36.4)$ & $\begin{array}{l}25.2- \\
49.3\end{array}$ & & \\
\hline Never married & 62 & $28(44.9)$ & $\begin{array}{l}30.5- \\
60.2\end{array}$ & & \\
\hline \multicolumn{6}{|l|}{ Region } \\
\hline Southern & 504 & $\begin{array}{l}208 \\
(41.3)\end{array}$ & $\begin{array}{l}36.1- \\
46.7\end{array}$ & $\begin{array}{l}F(1.91,1086.69)= \\
0.0302\end{array}$ & 0.9660 \\
\hline Central & 447 & $\begin{array}{l}188 \\
(42.0)\end{array}$ & $36.0-48.2$ & & \\
\hline Northern & 118 & $51(43.2)$ & $\begin{array}{l}34.5- \\
52.3\end{array}$ & & \\
\hline
\end{tabular}

Obstetrical history and uptake of three or more doses of IPTp-SP 
Table 4

displays the distribution of participants by obstetrical history that may affect uptake of optimal IPTp-SP doses. Distribution of participants by reported number of children (parity); shows that mothers with five or more children had the lowest uptake of optimal doses of SP (32\%) and the differences in SP uptake across parity was statistically significant $(p=0.0407)$. Study participants who started antenatal care in the first trimester had highest proportion of receiving optimal IPTp-SP (46\%) compare to those who commenced in second and third trimesters $(p=0.0004)$. There was a significant relationship between number of ANC visits and completion of recommended dosages of IPTp-SP $(p<0.001)$, with the highest uptake percent of $52 \%$ by those who made at least four visits to the ANC clinic.

\section{Table 4: Association between obstetrical history and uptake of three or doses of IPTp with SP}

\begin{tabular}{|c|c|c|c|c|}
\hline \multirow[t]{2}{*}{ Characteristic } & \multirow[t]{2}{*}{$\begin{array}{l}\mathrm{N}^{\dagger} \text { Total }= \\
1069\end{array}$} & $\begin{array}{l}\% \text { won } \\
\text { doses }\end{array}$ & \multirow[t]{2}{*}{ Rao-Scott F-test } & $\mathrm{p}$-value \\
\hline & & $\mathrm{n}^{\ddagger}(\%)$ & & \\
\hline
\end{tabular}

Parity

\begin{tabular}{llll} 
One child & 277 & $\begin{array}{l}125 \\
(45.0)\end{array}$ & $\begin{array}{l}37.4- \\
52.9\end{array}$ \\
\hline Two children & 244 & $\begin{array}{l}110 \\
(45.0)\end{array}$ & $\begin{array}{l}36.6- \\
53.7\end{array}$ \\
\hline Three children & 161 & $79(48.7)$ & $\begin{array}{l}40.1- \\
57.3\end{array}$ \\
\hline Four children & & & $29.0-49.3$ \\
\hline Five or more children & 254 & $51(38.6)$ & $26.8-$ \\
\hline & & $82(32.4)$ & 38.6
\end{tabular}

Timing of 1st ANC

visit

\begin{tabular}{|c|c|c|c|c|}
\hline 1st trimester & 222 & $\begin{array}{l}103 \\
(46.2)\end{array}$ & $\begin{array}{l}37.6- \\
54.9\end{array}$ & $F(1.94,1094.85)=7.9535$ \\
\hline 2nd trimester & 753 & $\begin{array}{l}327 \\
(43.5)\end{array}$ & $\begin{array}{l}39.1- \\
48.0\end{array}$ & \\
\hline 3rd trimester & 94 & $17(17.8)$ & $\begin{array}{l}10.5- \\
28.6\end{array}$ & \\
\hline
\end{tabular}

Number of ANC visits

\begin{tabular}{|c|c|c|c|c|c|}
\hline $4+$ & 500 & $\begin{array}{l}260 \\
(52.0)\end{array}$ & $\begin{array}{l}46.2- \\
57.7\end{array}$ & $\begin{array}{l}F(1.85,1045.90)= \\
31.8155\end{array}$ & $<0.001^{*}$ \\
\hline 3 & 413 & $\begin{array}{l}172 \\
(41.6)\end{array}$ & $\begin{array}{l}35.7- \\
47.7\end{array}$ & & \\
\hline $1-2$ & 156 & $15(9.9)$ & $6.1-15.4$ & & \\
\hline
\end{tabular}

${ }^{\dagger}$ weighted total frequency, ${ }^{\ddagger}$ weighted frequency of women who took three or more doses of IPTp-SP, *potential candidate for multivariate logistics regression because 
In this study population all women attended antenatal care at least once. Categorising the number of ANC visits as '1-2 only", ' 3 only' and ' 4 or more' the descriptive analysis results indicate that out of 1069 (weighted count) participants, 500 (46.8\%, 95\% Cl 43.4-50.2) attended ANC at least four times, 413 (38.6\%, 95\% Cl 35.2-42.1) made three ANC visits only and $156(14.6 \%, 95 \%$ CI 12.2-17.3) managed to attend ANC one-or two-times only during the entire gestation period. Cumulatively, the proportion of women that managed to attend at least three ANC clinics is $85.4 \%$ (95\% $\mathrm{Cl} 82.7-87.8)$.

\section{Insert Fig. 2 here}

Figure 2 indicates that almost two-third (64\%) of the participants who made four or more ANC visits started antenatal care in second trimester while 35\% initiated ANC in first trimester. Cumulatively $98 \%$ who made at least four ANC visits commenced ANC at the most in second trimester. Majority (84\%) who attended ANC thrice began their antenatal care in second trimester; and cumulatively $92 \%$ started antenatal care in second trimester at he most. Overall, $70.4 \%(95 \%$ Cl 67.1-73.6) initiated ANC in second trimester and 20.8\% (95\% Cl 17.9-24.0) began antenatal care in first trimester.

\section{Determinants of uptake of at least three doses of IPTp with SP}

The results of multiple logistic regression analysis presented in Table 5 indicate that women who visited ANC clinics three times only during pregnancy have a marginally significant lower odds of completing the recommended number of IPTp-SP doses than those who made at least four ANC visits $(p=0.060)$ after controlling for the relationships of the other predictors. Furthermore, women who made one or two ANC visits only have significant lowest odds of receiving at least three IPTp with SP doses than those women who attended ANC four or more times, adjusting for the other explanatory variables in the model $(p<0.001)$. 
Table 5: Estimates of Adjusted Odds ratios for the uptake of three or more doses of IPTp-SP

\begin{tabular}{|c|c|c|c|}
\hline Characteristics & $\begin{array}{l}\mathrm{N}^{\dagger}=1069 \\
\mathrm{n}^{\ddagger}\end{array}$ & Adjusted Odds Ratio (95\%Cl) & P-value \\
\hline
\end{tabular}

Education $^{\mathrm{a}}$

No formal education

125

1

Primary

699

$0.85(0.52-1.39)$

0.514

Secondary or higher

245

$0.95(0.51-1.75)$

0.860

Age group ${ }^{a}$

15-19

168

1

20-24

356

$1.37(0.81-2.34)$

0.241

25-29

237

$1.67(0.81-3.45)$

0.166

$30-34$

156

$1.17(0.51-2.69)$

0.708

35-39

108

0.97 (0.39-2.44)

0.956

$40+$

44

$0.99(0.35-2.87)$

0.993

Occupation $^{a}$

Unemployed

392

1

Self-employed

578

$0.94(0.66-1.33)$

0.730

Employed

99

1.07 (0.60-1.93)

0.813

Wealth $^{\mathrm{a}}$

Poorest

234

1

Poorer

238

$0.76(0.47-1.22)$

0.260

Middle

207

$0.73(0.46-1.18)$

0.197

Richer

199

$1.06(0.64-1.73)$

0.829

Richest

190

$0.92(0.51-1.67)$

0.784

Parity $^{a}$

One child

Two children

277

1

244

0.99 (0.57-1.77)

0.998

Three children

161

1.07 (0.55-2.06)

0.842

Four children

132

0.85 (0.36-1.99)

0.711

Five or more children

254

$0.73(0.32-1.66)$

0.452 


\section{Table 5: Estimates of Adjusted Odds ratios for the uptake of three or more doses of IPTp-SP}

Timing of 1st ANC visit*

\begin{tabular}{llll} 
2nd trimester & 753 & 1 & 0.453 \\
\hline 1st trimester & 222 & $0.85(0.56-1.29)$ & 0.164 \\
\hline 3rd trimester & 94 & $0.60(0.29-1.23)$ & 0.060 \\
\hline Number of ANC visits* & & 1 & $<0.001$
\end{tabular}

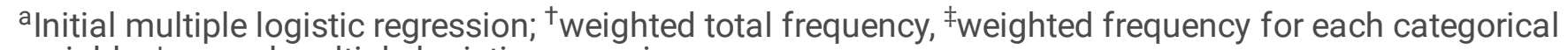
variable, *second multiple logistic regression

\section{Discussion}

The aims of the study are to estimate the proportion of and identify factors associated with the uptake of at least three doses of IPTp with SP among pregnant women in Malawi after adopting the updated WHO IPTp policy. The study findings have shown that overall proportion of women who took three or more doses of IPTp with SP is very low in the study population when compared to Roll Back Malaria (RBM) benchmark target of at least $80 \%$ for all pregnant women residing in areas with moderate-to-high malaria transmission in Africa [6]. Among the nine covariates that were analysed to explain the uptake of at least three doses of IPTp-SP among pregnant women in Malawi, only the number of ANC visits was found to affect the uptake of SP after controlling for the other predictors.

The descriptive data analysis results of this study revealed that proportion of receipt of three or more doses of IPTp with SP was highest among pregnant women making four or more ANC visits than those making fewer visits. Moreover, the adjusted odds ratio results indicate that pregnant women who attended ANC three times only and those who visited ANC one- or two-times only during gestation period had lower odds of receiving optimal doses of IPTp-SP compared to pregnant women who had made four or more ANC visits. This finding is consistent with studies done in Malawi [29, 36], Uganda [48], Tanzania [21, 31], Ghana [34, 38], Burkina Faso [32], Mali [33, 35], Cameroon, and in Benin [30].

Antenatal care clinic offers a platform for critical healthcare services and interventions such as health promotion, prevention, screening and diagnosis of diseases; aimed at improving maternal and foetal health [49, 50]. IPTp with SP is one of the preventive interventions being implemented at ANC clinics in Malawi. The 2012 updated WHO IPTp-SP policy recommends three or more doses of SP and that first dose should be administered as early as possible during the second trimester of gestation [20]. This means that early ANC initiation would increase the likelihood of receiving optimal SP doses as more visits would be made [20]. In this study majority initiated ANC after the first trimester but WHO recommends that pregnant women initiate ANC during the first trimester of pregnancy $[28,50]$. The study results show that less than half of the participants attended ANC clinics at least four times, suggesting low uptake of Focused antenatal care (FANC) model that was used at the time of the study 
as a standard. FANC model sets a minimum of four antenatal care visits and assessments by or under the supervision of a skilled attendant during an uncomplicated pregnancy $[28,50]$. The updated WHO IPTp policy was framed to be congruent with Focused antenatal care (FANC) model in order to increase uptake of optimal doses of IPTp with SP $[20,28]$. Worse still, only $52 \%$ of those women who made four or more ANC visits received the optimal doses of IPTp-SP. Moreover, ninety-eight percent of the women who attended ANC at least four times, initiated ANC clinic in the second trimester at the most. This suggests a missed opportunity to provide the recommended doses of IPTp with SP to women who managed at least four ANC visits [19].

The discrepancy between percentage of four or more ANC visits and percentage of receipt of at least three doses of SP could happen partly because of intermittent shortage of SP in the health facilities [37], poor fidelity in implementation of IPTp-SP intervention by individual healthcare providers as recommended in WHO policy brief that includes pregnant women taking IPTp-SP doses under Directly Observed Therapy (DOT) [51], and women's negative attitudes towards the use of the drug during pregnancy $[5,21,33,52]$. Another explanation could be that some of the ANC visits were not scheduled because of unexpected complications, hence SP doses were not dispensed.

The use of a nationally representative sample could strengthen the generalizability of the results to Malawian women with live births on uptake of optimal doses of IPTp with SP and its associated factors. However, the study had some limitations. First, analysis was limited on the variables that were available in the MDHS questionnaire associated with IPTp uptake; thus, the author could not explore other factors that could be relevant for this study, for example, beliefs/perception/attitude of the participants and their partners towards IPTp. Second, the study did not address issues of stockpiling and availability of SP doses at the health facilities. There is a possibility that women who attended WHO-recommended minimum number of ANC clinics failed to receive the prophylaxis because the commodity was not available. Third, the study excluded women who had a stillbirth and those whose children died before birth. The exclusion may have created selection bias that may have under-or overestimate the SP uptake if the excluded population differ from those included in the study in regard to SP uptake, ANC attendance, timing of first ANC visit, and any other explanatory variables. In this regard, the findings of this study are only generalisable to women with live children at birth. Finally, one of survey design inherent limitation is recall bias. Women may have reported past exposures/experiences with varying degree of accuracy because the primary source of the information collected from the research participants was self-reported. This may result in underestimation or overestimation of past experiences or events. However, some of these recall biases were minimised by interviewing the women less than two years after delivering live children.

\section{Conclusion}

Intermittent preventive treatment of malaria in pregnancy with sulfadoxine pyrimethamine (IPTp-SP) is effective in preventing the adverse consequences of malaria on birth outcomes. In Malawi, IPTp with SP is delivered at antenatal care clinics which are facility-based. This study was aimed to estimate the proportion of and identify factors affecting the uptake of at least three doses of IPTp with SP among pregnant women in Malawi after adopting the updated WHO IPTp policy. The results demonstrate that there is low uptake of the WHOrecommended three or more SP doses and this seems to be associated with the number of ANC visits. Moreover, the four or more ANC visits has limited effectiveness on the uptake of optimal SP doses in this study population. Thus, there is need for continued and varied efforts to increase both the uptake of optimal doses of IPTp with SP, WHO-recommended ANC number of contacts (visits) and effectiveness of ANC services. Future studies should

Page $15 / 22$ 
explore health facility-based factors that could influence IPTp uptake, such as accessibility of drugs at clinics (that includes stock levels of SP), skills and knowledge of ANC providers, pregnant women taking SP doses under Directly Observed Therapy (DOT) and if there is proper documentation of the SP uptake in women's ANC cards and any appropriate health facility ANC registers.

\section{Abbreviations}

IPTp-SP: Intermittent Preventive Treatment in pregnacy with Sulphadoxine Pyrimethamine; ANC: Antenatal Care; FANC: Focused antenatal care; MiP: Malaria in pregnancy; SP: Sulphadoxine Pyrimethamine; WHO: World Health Organization

\section{Declarations}

\section{Ethics approval and consent to participate}

The MDHS protocol was reviewed and approved by Malawi's National Health Sciences Research Committee and ICF Institutional Review Board. Interviewers informed prospective participants about the purpose of the study, procedures required of them if recruited, and that they had the right to volunteer whether or not to participate in the study. Informed consent was obtained from each participant before administering the questionnaire. Written informed consent was obtained from a parent or guardian for participants under 16 years old. The respondents were assured of privacy and confidentiality.

\section{Consent for publication}

Not applicable

\section{Availability of data and material}

The study used data from the Demographic and Health Surveys (DHS) Program with permission. The data are publicly available and may be requested from the DHS Program office on (https://www.dhsprogram.com/data/dataset_admin). The questionnaire used for the analyses is the women's questionnaire contained within the MDHS, which can be accessed publicly at https://www.dhsprogram.com/publications/publication-fr319-dhs-final-reports.cfm?cssearch=12978_1

\section{Competing interests}

The author declare that he has no competing interests.

\section{Funding}

Not applicable

\section{Author contributions}


SCA designed the study, performed the analysis and drafted the manuscript, edited and reviewed the manuscript and wrote. read and approved the final manuscript.

Author information

SCA is a Statistical Epidemiologist and Implementation Scientist working Malawi Military Health Services, Malawi Defence Force.

\section{Acknowledgements}

I am grateful to MEASURE DHS for providing me with the primary dataset.

Author details

Malawi Defence Force, Malawi Military Health Services, Kamuzu Barracks, Lilongwe, Malawi

\section{References}

1. Dellicour S, Tatem A, Guerra C, Snow R, ter Kuile F: Quantifying the number of pregnancies at risk of malaria in 2007: a demographic study. PLoS Med 2010, 7:e1000221.

2. Guyatt $H$, Snow R: The epidemiology and burden of Plasmodium falciparum -related anemia among pregnant women in sub-Saharan Africa. The American journal of tropical medicine and hygiene 2001, 64:36 44.

3. Menéndez C, D'Alessandro U, ter Kuile FO: Reducing the burden of malaria in pregnancy by preventive strategies. The Lancet Infectious Diseases 2007, 7(2):126-135.

4. Desai M, ter Kuile F, Nosten F, McGready R, Asamoa K, Brabin B, Newman R: Epidemiology and burden of malaria in pregnancy. Lancet Infect Dis 2007, 7:93 - 104.

5. Hill J, Hoyt J, van Eijk AM, D'Mello-Guyett L, Ter Kuile FO, Steketee R, Smith H, Webster J: Factors affecting the delivery, access, and use of interventions to prevent malaria in pregnancy in sub-Saharan Africa: a systematic review and meta-analysis. Plos Medicine 2013, 10(7):e1001488-e1001488.

6. Roll Back Malaria Partnership: The contribution of malaria control to maternal and newborn health. In: Progress \& impact Geneva: World Health Organization; 2014.

7. Agomo CO, Oyibo WA, Odukoya-Maije F: Parasitologic Assessment of Two-Dose and Monthly Intermittent Preventive Treatment of Malaria during Pregnancy with Sulphadoxine-Pyrimethamine (IPTP-SP) in Lagos, Nigeria. Malar Res Treat 2011, 2011:932895.

8. Malaria and Pregnancy [http://www.malariasite.com/pregnancy/]

9. Dimasuay KG, Aitken EH, Rosario F, Njie M, Glazier J, Rogerson SJ, Fowkes FJ, Beeson JG, Powell T, Jansson $\mathrm{T}$ : Inhibition of placental mTOR signaling provides a link between placental malaria and reduced birthweight. BMC medicine 2017, 15(1):1.

10. Rogerson SJ, Mwapasa V, Meshnick SR: Malaria in pregnancy: linking immunity and pathogenesis to prevention. The American journal of tropical medicine and hygiene 2007, 77(6 Suppl):14-22.

11. Steketee R, Nahlen B, Parise M, Menendez C: The Burden of Malaria in Pregnancy in Malaria-Endemic Areas. The American journal of tropical medicine and hygiene 2001, 64(1):28 - 35. 
12. Lagerberg RE: Malaria in pregnancy: A literature review. Journal of Midwifery and Womens Health 2008, 53(3):209-215.

13. Kayentao K, Garner P, van Eijk AM, Naidoo I, Roper C, Mulokozi A, MacArthur JR, Luntamo M, Ashorn P, Doumbo OK et al: Intermittent preventive therapy for malaria during pregnancy using 2 vs 3 or more doses of sulfadoxine-pyrimethamine and risk of low birth weight in Africa: systematic review and meta-analysis. Jama 2013, 309(6):594-604.

14. Eisele TP, Larsen DA, Anglewicz PA, Keating J, Yukich J, Bennett A, Hutchinson P, Steketee RW: Malaria prevention in pregnancy, birthweight, and neonatal mortality: a meta-analysis of 32 national cross-sectional datasets in Africa. The Lancet infectious diseases 2012, 12(12):942-949.

15. Guyatt H, Snow R: Impact of malaria during pregnancy on low birth weight in sub-Saharan Africa. Clin Microbiol Rev 2004, 17:760 - 769.

16. National Malaria Control Programme (NMCP) [Malawi]: Malawi Strategic Plan 2011-2015: Towards Universal Acess. In. Lilongwe, Malawi: NMCP; 2010.

17. Feng G, Simpson JA, Chaluluka E, Molyneux ME, Rogerson SJ: Decreasing burden of malaria in pregnancy in Malawian women and its relationship to use of intermittent preventive therapy or bed nets. PloS one 2010, 5(8):e12012-e12012.

18. WHO: Malaria in Pregnancy Guidelines for Measuring Key Monitoring and Evaluation Indictors. http://whqlibdoc.who.int/publications/2007/9789241595636_eng.pdf Accessed on Nov 24, 2015. 2007.

19. Andrews KG, Lynch M, Eckert E, Gutman J: Missed opportunities to deliver intermittent preventive treatment for malaria to pregnant women 2003-2013: a systematic analysis of 58 household surveys in sub-Saharan Africa. Malaria journal 2015, 14:1-10.

20. WHO: Updated WHO policy recommendation: intermittent preventive treatment of malaria in pregnancy using sulfadoxine-pyrimethamine (IPTP-SP). Geneva: World Health Organization; [Accessed on Nov 20, 2015]. Available from http://www.who.int/malaria/publications/atoz/who_iptp_sp_policy_recommendation/en/. In.: Geneva: World Health Organization; 2012.

21. Mpogoro FJ, Matovelo D, Dosani A, Ngallaba S, Mugono M, Mazigo HD: Uptake of intermittent preventive treatment with sulphadoxine-pyrimethamine for malaria during pregnancy and pregnancy outcomes: a crosssectional study in Geita district, North-Western Tanzania. Malaria journal 2014, 13(1):455-455.

22. ter Kuile FO, van Eijk AM, Filler SJ: Effect of sulfadoxine-pyrimethamine resistance on the efficacy of intermittent preventive therapy for malaria control during pregnancy: a systematic review. Jama 2007, 297(23):2603-2616.

23. ter Kuile FO, Steketee RW: Intermittent preventive therapy with sulfadoxine-pyrimethamine during pregnancy: seeking information on optimal dosing frequency. The Journal of infectious diseases 2007, 196(11):15741576.

24. WHO: Evidence review group: Intermittent preventive treatment of malaria in pregnancy (IPTp) with sulfadoxine-pyrimethamine (SP). In. Geneva: World Health Organization; Available from http://www.who.int/malaria/mpac/sep2012/iptp_sp_erg_meeting_report_july2012.pdf.; 2012.

25. Desai M, Hill J, Fernandes S, Walker P, Pell C, Gutman J, Kayentao K, Gonzalez R, Webster J, Greenwood B: Prevention of malaria in pregnancy. The Lancet Infectious Diseases 2018.

26. Mwendera CA, Jager C, Longwe H, Phiri K, Hongoro C, Mutero CM: Changing the policy for intermittent preventive treatment with sulfadoxine-pyrimethamine during pregnancy in Malawi. Malaria journal 2017, 
16(1):84.

27. Malawi National Malaria Control Programme: Revised guidelines for the treatment of malaria in Malawi. In. Lilongwe: Malawi Ministry of Health; 2013.

28. WHO: Provision of effective antenatal care, Integrated management of pregnancy and childbirth (IMPAC). Standards for maternal and neonatal care. Geneva: World Health Organization [Accessed on Nov 26, 2015]. Available from http://www.who.int/reproductivehealth/publications/maternal_perinatal_health/effective_antenatal_care.pdf. In.; 2006.

29. Azizi SC, Chongwe G, Chipukuma H, Jacobs C, Zgambo J, Michelo C: Uptake of intermittent preventive treatment for malaria during pregnancy with Sulphadoxine-Pyrimethamine (IPTp-SP) among postpartum women in Zomba District, Malawi: a cross-sectional study. BMC pregnancy and childbirth 2018, 18(1):108.

30. d'Almeida TC, Agboton-Zoumenou MA, Garcia A, Massougbodji A, Briand V, Imorou Y, Cottrell G: Field evaluation of the intermittent preventive treatment of malaria during pregnancy (IPTp) in Benin: evolution of the coverage rate since its implementation. Parasit Vectors 2011, 4:108.

31. Exavery A, Mbaruku G, Mbuyita S, Makemba A, Kinyonge IP, Kweka H: Factors affecting uptake of optimal doses of sulphadoxine-pyrimethamine for intermittent preventive treatment of malaria in pregnancy in six districts of Tanzania. Malaria journal 2014, 13(1):13-22.

32. Gies S, Coulibaly SO, Ky C, Ouattara FT, Brabin BJ, D'Alessandro U: Community-based promotional campaign to improve uptake of intermittent preventive antimalarial treatment in pregnancy in Burkina Faso. The American journal of tropical medicine and hygiene 2009, 80(3):460-469.

33. Hill J, Kayentao K, Touré M, Diarwara S, Bruce J, Smedley J, Doumbo OK, Kuile FOt, Webster J: Effectiveness of Antenatal Clinics to Deliver Intermittent Preventive Treatment and Insecticide Treated Nets for the Control of Malaria in Pregnancy in Mali: A Household Survey. PloS one 2014, 9(3):1-13.

34. Hommerich L, von Oertzen C, Bedu-Addo G, Holmberg V, Acquah PA, Eggelte TA, Bienzle U, Mockenhaupt FP: Decline of placental malaria in southern Ghana after the implementation of intermittent preventive treatment in pregnancy. Malaria journal 2007, 6:144-144.

35. Leonard N, Eric FB, Judith AK, Samuel W: Factors associated to the use of insecticide treated nets and intermittent preventive treatment for malaria control during pregnancy in Cameroon. Arch Public Health 2016, 74:5.

36. Nkoka O, Chuang T-W, Chen Y-H: Association between timing and number of antenatal care visits on uptake of intermittent preventive treatment for malaria during pregnancy among Malawian women. Malaria journal 2018, 17(1):211.

37. Pell C, Straus L, Andrew EVW, Meñaca A, Pool R: Social and cultural factors affecting uptake of interventions for malaria in pregnancy in Africa: a systematic review of the qualitative research. PloS one 2011, 6(7):e22452-e22452.

38. Amankwah S, Anto F: Factors Associated with Uptake of Intermittent Preventive Treatment of Malaria in Pregnancy: A Cross-Sectional Study in Private Health Facilities in Tema Metropolis, Ghana. Journal of tropical medicine 2019, 2019.

39. Mubyazi GM, Bygbjerg IC, Magnussen P, Olsen O, Byskov J, Hansen KS, Bloch P: Prospects, achievements, challenges and opportunities for scaling-up malaria chemoprevention in pregnancy in Tanzania: the perspective of national level officers. Malaria journal 2008, 7:135-135. 
40. World Health Organization Factsheet on the World Malaria Report 2013 [http://www.who.int/malaria/media/world_malaria_report_2013/en/]. In.

41. Kibusi SM, Kimunai E, Hines CS: Predictors for uptake of intermittent preventive treatment of malaria in pregnancy (IPTp) in Tanzania. BMC Public Health 2015, 15(1):540-540.

42. Mwandama D, Gutman J, Wolkon A, Luka M, Jafali J, Ali D, Mathanga DP, Skarbinski J: The use of intermittent preventive treatment in pregnancy and insecticide-treated bed nets for malaria prevention by women of child-bearing age in eight districts in Malawi. Malaria journal 2015, 14(1):1-10.

43. Launiala A, Honkasalo M-L: Ethnographic study of factors influencing compliance to intermittent preventive treatment of malaria during pregnancy among Yao women in rural Malawi. Transactions Of The Royal Society Of Tropical Medicine And Hygiene 2007, 101(10):980-989.

44. Ayubu MB, Kidima WB: Monitoring compliance and acceptability of intermittent preventive treatment of malaria using sulfadoxine pyrimethamine after ten years of implementation in Tanzania. Malaria research and treatment 2017, 2017.

45. National Statistical Office/Malawi, ICF: Malawi Demographic and Health Survey 2015-16. In. Zomba, Malawi: National Statistical Office and ICF; 2017.

46. Heeringa SG, West BT, Berglund PA: Applied survey data analysis: Chapman and Hall/CRC; 2017.

47. Hosmer Jr DW, Lemeshow S, Sturdivant RX: Applied logistic regression, vol. 398: John Wiley \& Sons; 2013.

48. Okethwangu D, Opigo J, Atugonza S, Kizza CT, Nabatanzi M, Biribawa C, Kyabayinze D, Ario AR: Factors associated with uptake of optimal doses of intermittent preventive treatment for malaria among pregnant women in Uganda: analysis of data from the Uganda Demographic and Health Survey, 2016. Malaria journal 2019, 18(1):250.

49. Tunçalp Ö, Pena-Rosas JP, Lawrie T, Bucagu M, Oladapo OT, Portela A, Gülmezoglu AM: WHO recommendations on antenatal care for a positive pregnancy experience-going beyond survival. J BJOG 2017, 124(6):860-862.

50. Pell C, Meñaca A, Were F, Afrah NA, Chatio S, Manda-Taylor L, Hamel MJ, Hodgson A, Tagbor H, Kalilani L: Factors affecting antenatal care attendance: results from qualitative studies in Ghana, Kenya and Malawi. PloS one 2013, 8(1):e53747.

51. WHO: World Health Organization, WHO Policy Brief for the Implementation of Intermittent Preventive Treatment of Malaria in Pregnancy using Sulfadoxine-Pyrimethamine (IPTp-SP), 2013 [http://www.who.int/malaria/publications/atoz/Policy_brief_IPTp-SP_implementation_11april2013.pdf.pdf]. In.: World Health Organization; 2013.

52. Bausell $\mathrm{L}$, Wolf $\mathrm{K}$ : Treatment uptake and availability of antimalarial drugs for intermittent preventative treatment in pregnant women in Malawi. In. Arlington, Va: USAIDIDELIVER PROJECT, Task Order 7; 2015.

\section{Figures}




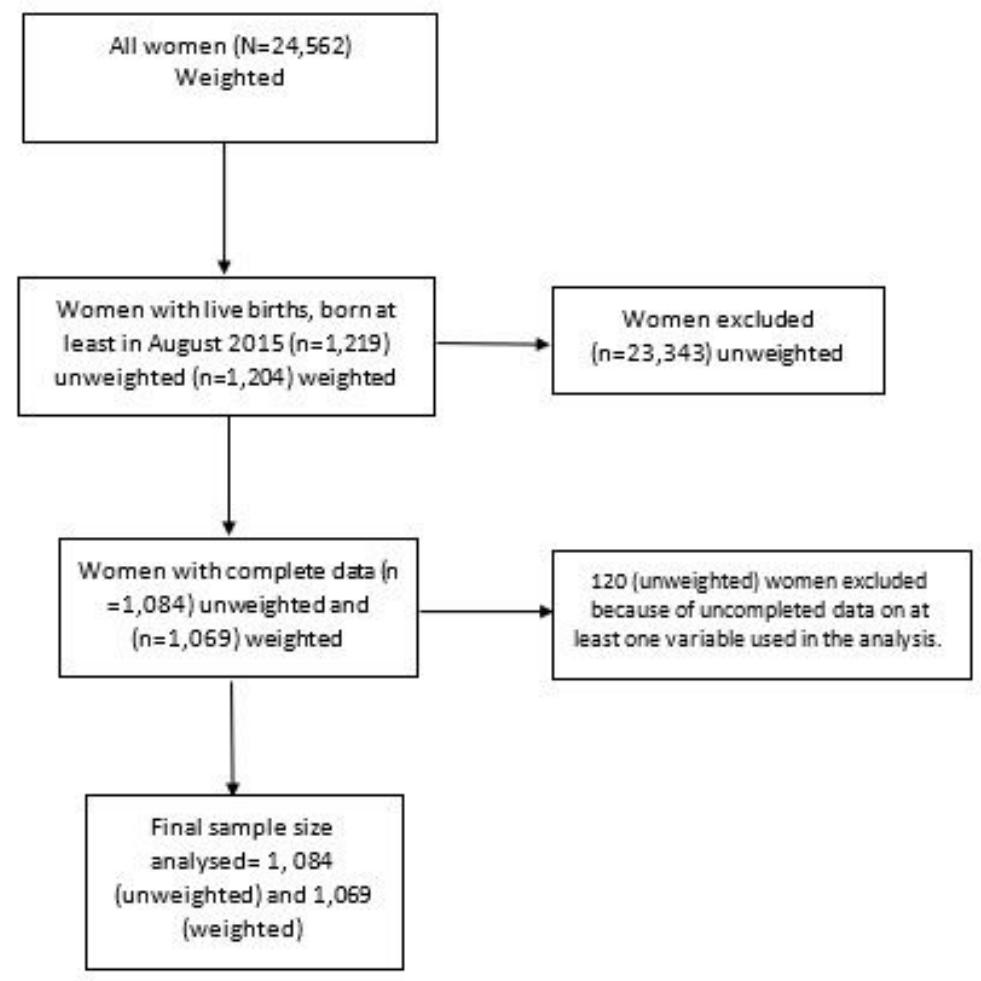

Figure 1

Flow Diagram of included sample in the study 


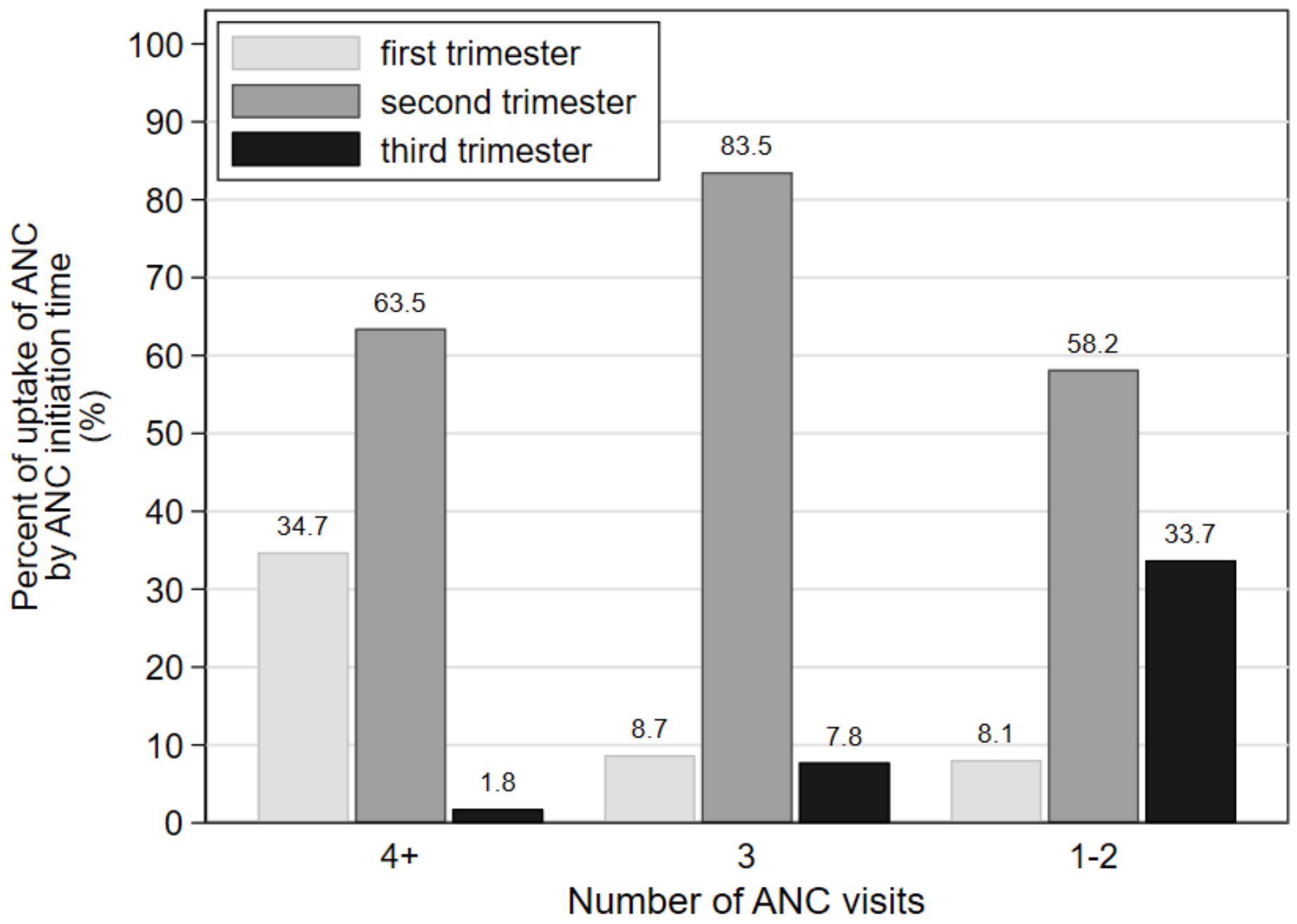

Figure 2

Proportion of uptake of antenatal care (ANC) against number of ANC visits by ANC initiation time

\section{Supplementary Files}

This is a list of supplementary files associated with this preprint. Click to download.

- STROBEchecklistcrosssectional.doc 